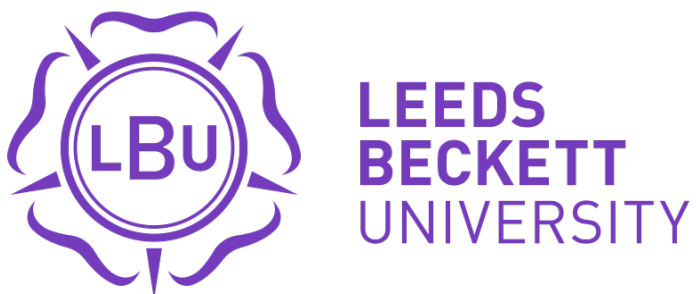

Citation:

Gold, J (2014) Revans reversed: focusing on the positive for a change. Action Learning: Research and Practice, 11 (3). 264 - 277. ISSN 1476-7333 DOI: https://doi.org/10.1080/14767333.2014.936927

Link to Leeds Beckett Repository record:

https://eprints.leedsbeckett.ac.uk/id/eprint/1496/

Document Version:

Article (Accepted Version)

The aim of the Leeds Beckett Repository is to provide open access to our research, as required by funder policies and permitted by publishers and copyright law.

The Leeds Beckett repository holds a wide range of publications, each of which has been checked for copyright and the relevant embargo period has been applied by the Research Services team.

We operate on a standard take-down policy. If you are the author or publisher of an output and you would like it removed from the repository, please contact us and we will investigate on a case-by-case basis.

Each thesis in the repository has been cleared where necessary by the author for third party copyright. If you would like a thesis to be removed from the repository or believe there is an issue with copyright, please contact us on openaccess@leedsbeckett.ac.uk and we will investigate on a case-by-case basis. 


\title{
Revans Reversed: Focusing on the Positive for A Change
}

\author{
Jeff Gold \\ Leeds Business School \\ j.gold@leedsmet.ac.uk
}

\begin{abstract}
The classical principles of action learning, based on the work of Revans, usually include working with problems as core. This article aims, by contrast, to show how a recent project of change has incorporated principles of Appreciative Inquiry based on social constructionism and positive psychology into an action learning process involving a wide range of participants. The concern for problems is considered showing that the process of diagnosing a problem can reinforce a deficit orientation. The key ideas of Appreciative Inquiry are presented, highlighting the purpose of finding out what is going on in terms of what is working well and in doing so, it becomes possible to build a picture of the strengths and virtues of what is happening at work. Based on findings from a recent project of culture shift in a design and production company, a process of Positive Action Learning (PAL) is considered.
\end{abstract}

Keywords: problems, culture, appreciative inquiry, positive action learning

\section{Introduction}

For many years now, the work of Reg Revans (2011) has been foundational for the practice of action learning. Often summarized as a Gold Standard, what have been called classical principles of action learning usually include working with problems as core. Further, such problems cannot be simple or mere puzzles, easily solved by access to expert knowledge, nor very easily available as we walk the streets, or sit in Caffe Nero. For Revans, the problems had to be intractable with no right answers, thus generating the potential for the set process to work, based on challenge and support, and more recently critique (Ram and Trehan 2009). Through questioning insight, new possibilities for action can be determined and possibly enacted. Over the last 20 years, there have been variations on this process, probably moving away from intractable problems, towards more functional or business driven problems, while preserving the learning focus. Our position in this paper, is not critique or even to challenge the value of the Revans tradition or the recent simplifications. Instead, we argue that there is something to be gained by showing appreciation for positivity, strength and virtue. That is, traditional action learning efforts focus on deficit situations while a positive approach seeks what is working well and learning from this.

The aim of the paper is to show how a recent project of change has incorporated principles of Appreciative Inquiry based on social constructionism and positive 
psychology into an action learning process involving a wide range of participants. To do this, we will briefly revisit the discourse on problems in action learning, before outlining how appreciation might also work within action learning. We show some of the findings from a programme currently operating in a UK-based but US-design and production company.

\section{From Problems to Appreciation in Action Learning}

According to Revans (1983), the relationship between learning and problems is the primary concern of action learning. It is a 'first principle' based on the logic of the combination of firstly. the presence of a difficult issue and secondly, salience for the learner, which together make the problem 'real'. Revans goes on to specify the possible responses when individuals are having to deal with an issue that 'they do not know how to address':
a. they sort through their past experience for relevant concepts
b. put concepts together in new ways
c. seek out new information that may bear upon the issue

The power of action learning is generated through the meaningfulness of the problem in that what is sought as way forward actually matters and that action is likely. There is less meaning if the problem is an exercise in thinking, or even worse, an academic process based on a disconnected theory. Whatever happens needs to provide for action so that learning becomes possible.

Becoming aware of problems which can be considered in a set was a key feature of Revans theory of action, expressed as a science of praxeology of cyclical systems alpha, beta and gamma. In system alpha, a learner becomes aware of the problem which in turn becomes the focus for consideration in the set. Problems identified are connected to a range of factors or variables both internal and external to a learner that need to be considered so that a possibility for action can be found, the link to system beta.

Of course not all factors can be identified with precision, nor can all problems be structured to find the next steps. While all problems, to a greater or less extent, can be seen as 'undesirable' situations to which a solution needs to be found which is seen as more favourable, there are some important differences between problems (Smith 1988). One difference is the extent to which what is called a problem can be structured so that what is undesirable can be defined and framed for attention (Rein and Schon 1977). Unstructured problems are more difficult to state possibly because of a failure to understand the current state or set out the desired future state or how the means to bridge a gap between current and future state can be addressed. The very process of defining and framing calls attention to another source of differences based on preferences, perceptions or the language of those involved. This makes for wide variations in how problems are understood, based on variations of subjective considerations, even if objective conditions and facts are considered the same (Eden 
and Sims 1979). Problems have their existence partly in the way they are conceived or talked about. For example, as Grint (2005) has shown, for many leaders, it is how problems are constructed which becomes crucial to their actions as leaders.

Both objectively and subjectively, unstructured problems can be difficult to define and manage. Multiple factors and variables may be present in the situation arising from multiple causes and multiple interests, giving an impression of a 'mess' (Ackoff 1981) or 'equivocality' (Weick 1979) or even a 'wicked problem' (Rittel and Webber 1973). The latter in particular were characterized as, among other things, having no definite formulation, having no true or false solutions and providing the cover as a symptom for another problem. We could also add, as identified by Checkland (1981), definitions and meanings made at one time can change in another.

Unstructured problems are the likely types of problem that Revans would have seen as intractable without obvious solution, and therefore suited to action learning. Much of Revans' consideration, of course, related to the work of managers. So, problems could also be seen as opportunities to advance 'the attainment of their goals' (Revans 2011 , p.3), suggesting that action learning, in traditional terms, serves the interests of managers. This does raise an interesting dilemma; indeed, the focus on problems can overlook the working of dilemmas, which requires a both/and mode of consideration rather than problems with solutions (Billig 1996). Dilemmatic thinking has to recognize the importance and, a word we will use below, appreciation of ongoing interdependence and relationship with others, who may well have their own views of any situation. It is therefore quite possible that the problem/solution reasoning can also lead to antagonism of the interests of others, creating new undesirable situations sooner or later. Given that many of the problems identified by managers can relate to issues of change or bringing about a new situation which can disturb others (Smith 1995), it is not surprising that interdependence be overlooked and others considered as problematic, e.g. as resistors in change. As managers face their intractable problem, one of the responses is to frame the situation as one that is diseased, requiring a cure. Schön and Rein (1994), for example, show how framing often draws on metaphor to help find a direction. If there is a problem, a diagnosis is needed before the cure or solution can be generated. However, the very process can reinforce a deficit orientation.

Research on change and cultural programmes would suggest that, despite positive intentions and aspirations, are often frame in terms of problem/solution but might encounter oppositional forces which prevent progress (Kotter 1995; Ogbonna and Wilkinson 2003). Even if short term evidence suggests movement, over time, previous conditions can be restored. In the hands of managers, who could well view an organisation in unitarist terms, thus avoid the complexity of considering an organisation as a naming or categorization of an entity which is difficult or impossible to observe that, as pointed out by Sandelands and Drazin (1989), 'betoken a netherworld between fact and fiction'. That is, far from unity, most organisations might be best considered as 'nets of collective actions' (Czarniawaska-Joerges (1993), each with their own versions of what is right and good to do and it is this that needs to be reconsidered through Appreciative Inquiry (AI). 
Al has its origins in conversations regarding the limitations of traditional approaches to inquiry and theory that focus on problems to be solved and in so doing, perhaps construct, perpetuate and deepen the problems. What might be sacrificed is the generative power of inquiry (Gergen 1978). Instead, as argued by Cooperrider and Srivastva (1987), it becomes possible through conversations to find out what works well in an organisation and how. Further through this process of discovering valuable knowledge of the strength and virtue in an organisation, it becomes possible to share such knowledge and stimulate learning, questioning even but leading to potential of designing new action possibilities elsewhere. Al, of course, is theoretically stimulated by the ideas of social constructionism, which Gergen (1985: 3) explains as 'elucidating the processes by which people come to describe, explain, or otherwise account for the world in which they live'. For Al, there are two aspects to this: 1 . Completion of the elucidation to allow gathering of descriptions, explanations or accounts of meanings made between people, and 2 . The conversations held to complete the process. The second as aspect gives centrality to what Gergen (1995) refers to as a 'relational nucleus', where meaning is made by the co-ordinated actions of at least two persons, usually through conversation. It is always possible for conversations to fail, as pointed out by Gergen:

'If others do not recognisably treat one's utterance as meaningful, if they fail to co-ordinate themselves around such offerings, one is reduced to nonsense.'

(Gergen 1995:37)

However, in Al the purpose is to find out what is going on in terms of what is working well and in doing so, it becomes possible to build a picture of the strengths and virtues of what is happening at work. Further, through the questioning process within conversations, energy and vitality are given to what is happening (Bushe 2011). Al practitioners are both the inquirers but also the agents for positive movements, although as social constructionists would argue, what is considered positive or right or good is also a meaning made that is 'highly circumscribed by culture, history or social context' (Gergen 1985:6). The Al process nevertheless, in a particular place and time, has the potential to find and make positive changes, which contrast to the traditional concern with problems. It is the contrast and balance which is the concern, rather than a 'full-on' messianic transformation call. Figure 1 shows the dimension along which Al can take place. 


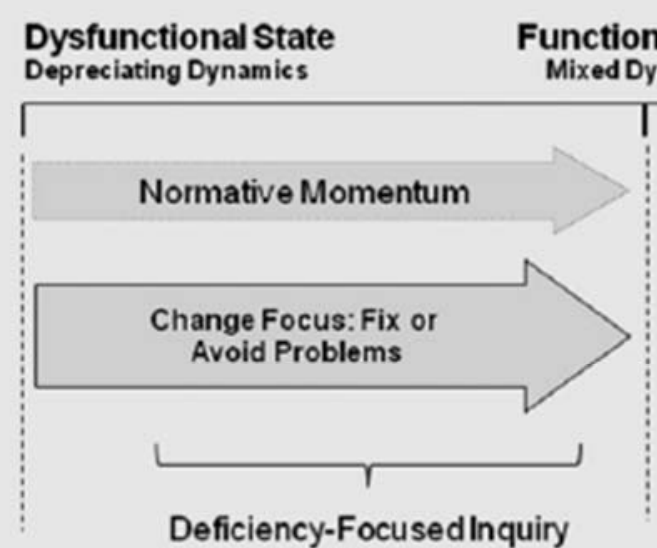

Deficiency-Focused Inquiry
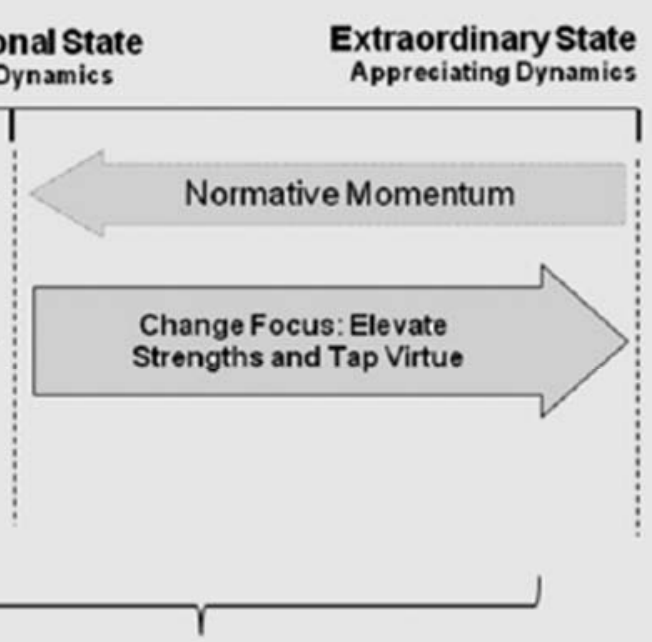

Appreciative Inquiry

\section{Figure 1:}

Source: Bright (2009: 3)

Al sees the move along the dimension as part of a cycle composed of four stages or phases, shown in Figure 2.

\section{The Al Cycle}

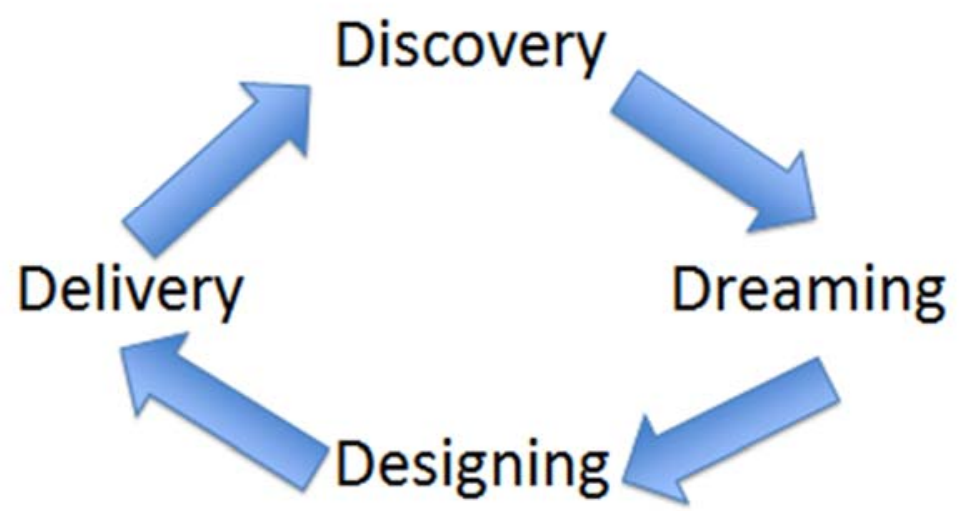

Figure 2: The Al Cycle 


\section{Source: Cooperrider and Whitney 2000, p. 614}

The Al cycle can be understood and used quite flexibly, with no rules on times for stages. It can be seen as a contrast and alternative to a problem solving cycle. Instead, for example, the Discovery phase is concerned with finding out what is working well with consideration to the overall theme of the project. Through conversations, data can be gathered through stories and responses to questions, which are tilted towards positive interpretations, and what factors underpinned such views. Through this relational process, versions of truth are constructed. In Al, the view presented is valued and therefore requires a response that is complementary. As data is collected and analysed, patterns, themes and good examples of practice are used to work out new possibilities for action and change. Because $\mathrm{Al}$ is concerned with what works and what is valued, it becomes possible to provide a glimpse of what could happen in the future that builds on what is already happening. This allows the phase of Dreaming to be completed and the researcher has a chance to share findings with others in the project, leading then to Design. Just what is designed depends on the data collected and the meanings made in dreaming. Whatever is designed, whether it involves new systems, structures, forms of engagement, changes to work or behaviour, it involves action and an attempt to involve others in the action. Of course, such change does not happen without efforts to bring others into the process and again, this achieved through conversations and the making of meanings (Ford and Ford 1995). Both Dreaming and Design may require good skills of dialogue (Bohm 2013) as future possibilities are considered. It is also likely that the involvement of more voices becomes part of the project, adding to the data. Whatever happens can provide data and the cycle can begin again.

The refocus of attention from intractable problems towards strength and virtue makes action learning a very convenient process for organisation change and development. There may still be difficult and intractable problems, but the concern to tackle these is made less prominent, given the vagaries of interpretation of problem difficulty and intractability. Instead, there is much learning and action to be gained by considering the positive and in the next section we give a sense of this accomplishment from a project of culture shift in Company B.

\section{Positive Action Learning (PAL)}

To consider how action learning can work with Al, the case of Company B, a UK-based but US-owned design and production company is considered. With a history stretching back to the early years of the twentieth century, the company grew in the US to become a leader in its field, producing a consumer good based on high quality design for particular occasions throughout the year.

In the 1950s, the company, while remaining in family ownership, expanded into Europe and Company B was established, eventually as a PLC. Company B grew less as a brand but mostly as a leading supplier to large retail organisations and smaller independents. In 2012 they employed 2,200 staff across the UK, covering design, 
customer servicing and management and manufacturing. It had the largest product range in the UK market with almost 20,000 designs available in any one year.

During the recession, following the global financial crisis in 2008, Company B found that it faced a range of issues that challenged its position. The market for its products was flat and its own share was under attack from various competitors, including an online and low cost producers. Some of the larger retailers were also considering more vertical structures for their products. As a result, production fell by around $15 \%$ and there were redundancies of around $10 \%$.

Company B's board, perhaps belatedly, realized that a realignment of the business and strategy was needed, with recognition that first and foremost they were a consumerled business and that, while retail customers were critical, the most important relationship was with the consumer. Yet brand awareness for Company B was with the retail customers rather than the consumers.

It was soon recognized by the learning and development manager that the redirection of the organisation would also require a shift in culture, even as staff were being made redundant. The project initiated sought to build a culture of engagement to enable change agility. The projects objectives were set to:

1. Share best practice across the organisation through building effective networks

2. Re-energise communication processes

3. Reinforce a culture of leadership at all levels to create a non-hierarchical "power base"

As a means of meeting these objectives, PAL was seen as way of articulating the desired culture and sharing and acting upon based practice. The approach would therefore combine action learning with Al. To begin this process, a group of 5 managers and supervisors were asked to join the project.

At the first meeting of this group, both action learning and Al were introduced. The first step took problem identification as a way of setting the current state of the culture. We posed the question: What were the key cultural problems and challenges for Company B?

Through problem surfacing, based on the nominal group technique (Delbecq 1975), three themes emerged:

1. Strategy

2. Visibility

3. Communication

Each theme was then defined as a problem, with a main question set: 
We have a 1 year strategy focused on delivery: we don't see a year 2 and 3 plan There is a lack of ongoing communication: update/ where are we winning. Politics influences the strategy delivery and we aren't walking the talk

The main question: How do we ensure alignment to the strategy?

\section{Visibility}

Lack of clear visibility of the leadership team (walking the talk, being aligned, listening and being seen together). Lack of a clear detailed vision/plan for year $1 / 2 / 3$ with outcomes, actions and timings. Lack of engagement of all to really believe in the future.

The main question: What is the plan/strategy with timelines and what do we look like in 3 years?

\section{Communication}

We don't have a common understanding of what the true issues are. There is no honest and open regular update on business performance with sufficient detail for people to take action. We aren't energising people around what they can/ need to do.

The main question: What are the true issues and what stops us from being open about them?

The importance of this process was to enable the group to set some baseline indicators for progress. However, rather than dwell on the problems and deficiencies of the present, many of which had long historical roots, Al was introduced. The first step in this process was to understand how to hold an appreciative interview. Each person was asked to consider and then write down postcard responses to the following:

1. Identify an example known to you of a really good work practice (rgwp)

2. What happened that made it rgwp? - write a sentence

3. How did the rgwp happen and why? - write a paragraph

4. What are the implications of this rgwp for others in the company? - bullet point

Aware of the process, the questions were then to conduct an appreciative interview. Working in pairs, each person practiced interviewing by using the same questions as a guide. This allowed an understanding of appreciation of what was working well and the value attached. The immediate reaction was how empowering and interesting the conversations had been and how this way of talking could enable change. At this first 
meeting, the group agreed to find others to interview in parts of the business that they did not usually visit. This allowed another action learning reversal, unfamiliar appreciation in unfamiliar settings.

The group held various appreciative interviews throughout Company B, making records of what was working well and how learning from this process could be taken to others in the business. At the first review meeting, the findings were shared.

The key words from the appreciative interviews were recorded and shown as Table 1:

\begin{tabular}{|c|c|c|}
\hline $\begin{array}{l}\text { - } \text { Dynamic: } \\
\text { - } \text { Resilience to } \\
\text { - } \text { Talent retention } \\
\text { - Charismatic } \\
\text { leadership team } \\
\text { - Alignment: all } \\
\text { working to the } \\
\text { same goal } \\
\text { Clear } \\
\text { communication: } \\
\text { team days } \\
\text { Celebrate success: } \\
\text { recognition } \\
\text { - Showing } \\
\text { commitment: } \\
\text { saying it and doing } \\
\text { it } \\
\text { Credibility }\end{array}$ & $\begin{array}{ll}\text { - } & \text { Engagement } \\
\text { - } & \text { Environment/ } \\
\text { - } & \text { Simplture: attractive } \\
& \text { complex } \\
\text { - } & \text { Work life balance } \\
\text { - } & \text { Cross functional } \\
\text { - } & \text { Pride in } \\
\text { - } & \text { Echievements } \\
\text { - } & \text { Influence to } \\
\text { business } \\
\text { - Perceived value } \\
\text { - Proactive } \\
\text { - Empathy } \\
\text { - Positive } \\
\text { influencers } \\
\text { - Mutual respect: } \\
\text { boss to team; } \\
\text { team peers }\end{array}$ & $\begin{array}{ll}\text { - } & \text { Collaborative } \\
\text { - } & \text { Visibility } \\
\text { - } & \text { Ownership } \\
\text { - } & \text { Protected from } \\
& \text { reality vs change } \\
& \text { agile } \\
\text { - } & \text { Flexibility } \\
\text { - } & \text { Knowledge } \\
\text { sharing } \\
\text { - Embracing } \\
\text { learning from } \\
\text { mistakes } \\
\text { - Empowered to } \\
\text { make things } \\
\text { better as part of } \\
\text { your job } \\
\text { Honesty: no } \\
\text { hidden agendas }\end{array}$ \\
\hline
\end{tabular}

Table 1: key words from the appreciative interviews

The ideas for action elsewhere in the business included:

1. Share knowledge

2. Swap logistics people into manufacturing

3. Build a culture of networking: e.g. Cross functional workshops: share specialist skill sets

4. Practice empowerment: allow different decisions to be made and adopt a true coaching culture

5. Learn from other businesses / areas

6. Consistent communication messages

how are we performing and what can I do 
- $\quad$ acting on decisions quickly

7. Celebrate success and recognise people: little treats and thank yous/ individuals and teams

8. Honesty: tell it how it is and enable individuals to rise to the challenges

9. Simplify: give it a go and don't wait for Chrysalis. Break the process to ensure lean/ speed. Be less of a perfectionist culture

10. Alignment and detail: clear accountability from the exec down

Most importantly, the group was able experience a process of engagement with staff that not revealed what was working but how the construction of that revelation was part of the process. It was found that there were a number of 'first times' in the interviews; that is, those interviewed often felt that no one had taken any interest in what they were doing and what was valued. Gaining 'confidence' and feeling 'empowered' were consistent findings.

The group moved from discovery to dreaming in the Al cycle. This centred on the question:

How do we start to build a network of positive influencers within Company B using the Al approach?

As a way of monitoring progress, the groups assessed their impressions against baseline indicators the emerged from the first meeting. These are shown in Table 2. The scores reflect movement from the starting point of 0 , on a scale of $0-10$. Means are shown

\begin{tabular}{|c|c|}
\hline Strategy & \\
\hline $\begin{array}{l}\text { We have a } 1 \text { year strategy focused on } \\
\text { AOP delivery: we don't see a year } 2 \text { and } \\
3 \text { plan }\end{array}$ & 3.5 \\
\hline $\begin{array}{l}\text { There is a lack of ongoing } \\
\text { communication: update/ where are we } \\
\text { winning }\end{array}$ & 4 \\
\hline $\begin{array}{l}\text { Politics influences the strategy delivery } \\
\text { and we aren't waking the talk }\end{array}$ & 3.75 \\
\hline Visibility & \\
\hline $\begin{array}{l}\text { Lack of clear visibility of the leadership } \\
\text { team (walking the talk, being aligned, } \\
\text { listening and being seen together) }\end{array}$ & 3.5 \\
\hline
\end{tabular}




\begin{tabular}{|l|c|}
\hline $\begin{array}{l}\text { Lack of a clear detailed vision/plan for } \\
\text { year } 1 / 2 / 3 \text { with outcomes, actions and } \\
\text { timings }\end{array}$ & 3.25 \\
$\begin{array}{l}\text { Lack of engagement of all to really } \\
\text { believe in the future }\end{array}$ & 3.25 \\
Communication & \\
$\begin{array}{l}\text { We don't have a common understanding } \\
\text { of what the true issues are }\end{array}$ & 3.5 \\
$\begin{array}{l}\text { There is no honest and open regular } \\
\text { update on business performance with } \\
\text { sufficient detail for people to take action }\end{array}$ & 3.5 \\
$\begin{array}{l}\text { We aren't energising people around } \\
\text { what they can/ need to do }\end{array}$ & \\
\hline
\end{tabular}

Table 2: Movement against the baseline - First Review

The dreaming turned into designing, through the articulation of a project plan. Firstly, the PAL process could be spread to others. Each member of what would now be called the Champion Group could facilitate a group. The designing took the form of a protonetwork of PAL groups, as shown in Figure 3.

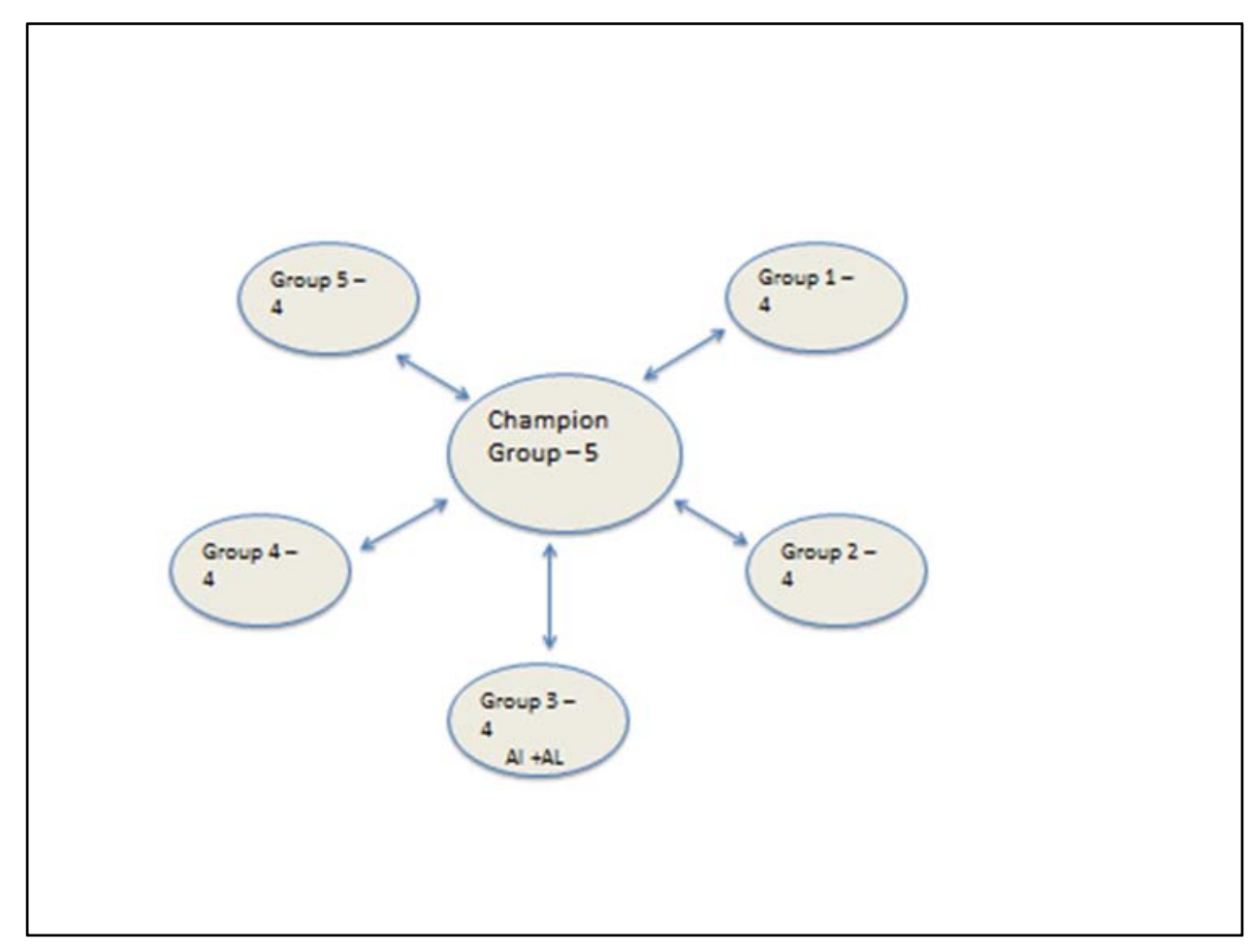


Figure 3: A Proto-Network of PAL Groups

The designing sought to replicate the experience of the champion group but also, through the attention to positive stories, there was the potential of more people constructing positive realities but also providing learning for others. There was also now a strong potential for gathering more data from the business of what was working, as each sub-group would be completing their own discovery phase.

It was also decided to agree some key themes with the Board sponsors for the groups to work on. Examples could be:

- Recognition

- Dynamism

- Alignment/ Collaboration

- Confidence in the brand

- Inspirational leadership at all levels

Two sponsors from the Board were found and agreed to receive feedback from the process.

The champion group attracted 20 others to learning about action learning and $\mathrm{Al}$, using the same process as their own. At the end of the two hour training, volunteers to join a PAL group were requested. Significantly, all 20 agreed to participate and were formed into 5 PAL groups.

At next review, it was evident that the five PAL groups had become four and only one meeting had been held. However, the champion group had been able to report progress in the business. One story related to a meeting of managers where without prompting, a manager had been able focus in positive practice and what was working, which created a good atmosphere among the managers. The CEO was also aware that 'stories' were important and that the board 'do not see enough of the good often enough'. At this point, the champion group were gaining confidence; their scores against the baseline are shown in Table 3 


\begin{tabular}{|c|c|}
\hline $\begin{array}{l}\text { Strategy } \\
\text { We have a } 1 \text { year strategy focused on } \\
\text { AOP delivery: we don't see a year } 2 \text { and } \\
3 \text { plan }\end{array}$ & 5.8 \\
\hline $\begin{array}{l}\text { There is a lack of ongoing } \\
\text { communication: update/ where are we } \\
\text { winning }\end{array}$ & 5.6 \\
\hline $\begin{array}{l}\text { Politics influences the strategy delivery } \\
\text { and we aren't waking the talk }\end{array}$ & 5.4 \\
\hline Visibility & \\
\hline $\begin{array}{l}\text { Lack of clear visibility of the leadership } \\
\text { team (walking the talk, being aligned, } \\
\text { listening and being seen together) }\end{array}$ & 4 \\
\hline $\begin{array}{l}\text { Lack of a clear detailed vision/plan for } \\
\text { year } 1 / 2 / 3 \text { with outcomes, actions and } \\
\text { timings }\end{array}$ & 4 \\
\hline $\begin{array}{l}\text { Lack of engagement of all to really } \\
\text { believe in the future } \\
\text { Communication }\end{array}$ & 5.6 \\
\hline $\begin{array}{l}\text { We don't have a common understanding } \\
\text { of what the true issues are }\end{array}$ & 5 \\
\hline $\begin{array}{l}\text { There is no honest and open regular } \\
\text { update on business performance with } \\
\text { sufficient detail for people to take action }\end{array}$ & 5.4 \\
\hline $\begin{array}{l}\text { We aren't energising people around } \\
\text { what they can/ need to do }\end{array}$ & 4.6 \\
\hline
\end{tabular}

Table 3: Movement against the baseline - Second Review

By the time of the third review with the champion group, a process for recording interview results was in place and all groups were now engaged with several examples of what was working. Participants were feeling the sense of empowerment as they held interviews and were also learning the importance holding such conversations 'outside the silos'. Importantly, there was a feeling that 'the ship was steadying, with light at the end of the tunnel', although a continuing tension between cynicism and credibility remained. 


\section{Summary}

In a key work on changing organizational cultures, Alvesson and Sveningsson (2008) highlight key tensions between what is said and portrayed as desirable, and what is actually experienced as thoughts and feelings, captured through descriptions of what is done. If we also accept the fragmented and likely disunity of most organisations (compared with unitarist views), it becomes quite likely that differing versions of what is right, good and valued will be present. Of course, such variation can easily be construed as a problem, even wicked, in programmes of change and culture shift. Certainly action learning might be considered as the process to tackle such a problem. However, if we make a broad assumption that for most of time, most of the workforce in any organization is seeking to do things that are right, good and valued, even if others have differing versions, then it just as important to set a direction to explore what is working as a source of learning and action. Along with Edmonstone (2014), we have argued for more interest to be shown in what is working well through Al.

In the short time Al has been working in Company B, within a PAL process, there have been, even at times of restructuring, surprising and interesting stories of empowerment, people unexpectedly coming together and a more energizing experience of working. There was a talk-based movement referring to the 'old $v$ new' Company B which had even attracted the interest of managers. The project that is reported is only partially complete and perhaps this will always be the case. However, what has been interesting is how Al combined with PAL has managed to enroll a reasonably large group of positive participants, with the potential for more. It can therefore, possibly, be added to the list of large group interventions, such as Open Space and Future Search. What is important is how, through storied conversations, the numbers who are prepared to make change a possibility can also ensure it becomes a reality.

Finally, while Revans might have baulked at the way the action learning nomenclature has been usurped, he surely would have recognized the value to be gained by the redirection towards what is working and what is valued by the workforce. Further, since it is often managers that construe problems with the same workforce, the conversational aspect that is a requirement in $\mathrm{Al}$, can also serve to make with others a joint version of what their future can be.

\section{References}

Alvesson, M., and S. Sveningsson, 2008. Changing organizational culture: Cultural change work in progress. New York: Routledge.

Ackoff, R. 1988. The art and science of mess management. Interfaces 11, no.1: 20-26. 
Billig, M. 1996. Arguing and thinking: A rhetorical approach to social psychology. Cambridge University Press, Cambridge.

Bohm D. 2013. On dialogue. London: Routledge

Bright, D. 2009. Appreciative inquiry and positive organizational scholarship. $O D$ Practitioner 41, no.3: 2-7.

Bushe, G.R. 2011. Appreciative inquiry: Theory and critique. In The Routledge Companion To Organizational Change eds. D. Boje, B. Burnes and J. Hassard, 87-103. Oxford, UK: Routledge.

Checkland, P. 1981. Systems thinking, systems practice. John Wiley, New York.

Cooperrider, D.L., and S. Srivastva, 1987. Appreciative inquiry in organizational life. In Research In Organizational Change And Development eds R.W. Woodman and W.A Pasmore, 129-169. Stamford, CT: JAI Press.

Cooperrider, D., and D. Whitney, 2000. A positive revolution in change. In Handbook of Organizational Behavior ed. R.T. Golemiewwski, 611-629. Second Edition, Revised and Expanded CRC Press

Czarniawska-Joerges, B. 1993. The Three-dimensional organization. Lund:

Studentlitteratur.

Delbecq, A., A. Van de Ven, and D. Gustafson, 1975. Group techniques for program planning: A guide to nominal group and delphi. Chicago: Scott Foresman.

Edmonstone, J. 2014. On the nature of problems in action learning. Action Learning Research and Practice 11, no.1: 25-41.

Ford, J.D., and L.W. Ford, 1995. The role of conversations in producing intentional change in organizations. Academy of Management Review 20, no.3: 541-70.

Gergen, K. J. 1978. Towards generative theory. Journal of Personality and Social Psychology, 36 No. 11: 1344- 1360.

Gergen, K.J. 1985. Social constructionist inquiry: Context and implications. In The Social Construction of the Person eds K..J. Gergen and K. Davis, 130-180. New York:Springer Verlag.

Gergen, K.J. 1995. Relational theory and discourses of power. In Management and Organization: Relational Alternatives to Individualism eds D-M. Hosking, H.P. Dachler and K.J. Gergen, 29-51. Avebury, Aldershot.

Grint, K. 2005. Problems, problems, problems: The social construction Of 'leadership'. Human Relations 58, no. 11: 1467-1494 
Kotter, J. 1995. Leading change: why transformation efforts fail. Harvard Business Review 73, No.2: $59-67$.

Ogbonna, E., and B. Wilkinson, 2003. The false promise of organizational culture change: A case study of middle managers in grocery retailing. Journal of Management Studies 40, No. 5:1151- 1178.

Ram, M., and K. Trehan, (2009), Critical by design: enacting critical action learning in a small business context. Action Learning Research and Practice 6, No.3: 305-318.

Rein, M., and D. A. Schon, 1977. Problem setting in policy research. In Using Social Research in Public Policy Making ed. C. H. Weiss, 235-251. Lexington: D. C. Heath \& Co.

Revans, R. 1983. The ABC of action learning. Chartwell Bratt, Buckley, Kent

Revans, R. 2011. ABC of action learning. Aldershot: Gower.

Rittel, H. W. J., and M. M. Weber. 1973. Dilemmas in the General Theory of Planning. Policy Sciences 4, no. 2: 155-169

Sandelands, L., and R. Drazin, 1989. On the language of organization theory. Organization Studies 10, No. 4: 457-478.

Schön, D., and M. Rein, 1994. Frame reflection. New York, NY: Basic Books.

Smith, G.F. 1988. Towards a heuristic theory of problem structuring. Management Science 34, No. 12: 1489-1506.

Smith, G.F. 1995. Classifying managerial problems: An empirical study of definitional content. Journal of Management Studies 32, no. 5: 679-706.

Weick, K. 1979. The social psychology of organizing. New York: McGraw-Hill. 